\title{
The Danish Neuro-Oncology Registry
}

This article was published in the following Dove Press journal:

Clinical Epidemiology

25 October 2016

Number of times this article has been viewed

\section{Steinbjørn Hansen}

Department of Oncology, Odense University Hospital and Institute of Clinical Research, Faculty of Health Sciences, University of Southern

Denmark, Odense, Denmark
Correspondence: Steinbjørn Hansen Department of Oncology, Odense University Hospital and Institute of Clinical Research, Faculty of Health Sciences, University of Southern Denmark, Sdr. Boulevard 29, DK-5000 Odense C, Denmark Email steinbjoern.hansen@rsyd.dk
Aim of database: The Danish Neuro-Oncology Registry (DNOR) was established by the Danish Neuro-Oncology Group as a national clinical database. It was established for the purpose of supporting research and development in adult patients with primary brain tumors in Denmark.

Study population: DNOR has registered clinical data on diagnostics and treatment of all adult patients diagnosed with glioma since January 1, 2009, which numbers approximately 400 patients each year.

Main variables: The database contains information about symptoms, presurgical magnetic resonance imaging (MRI) characteristics, performance status, surgical procedures, residual tumor on postsurgical MRI, postsurgical complications, diagnostic and histology codes, radiotherapy, and chemotherapy.

Descriptive data: DNOR publishes annual reports on descriptive data. During the period of registration, postoperative MRI is performed in a higher proportion of the patients (Indicator II), and a higher proportion of patients have no residual tumor after surgical resection of the primary tumor (Indicator IV). Further data are available in the annual reports. The indicators reflect only minor elements of handling brain tumor patients. Another advantage of reporting indicators is the related multidisciplinary discussions giving a better understanding of what actually is going on, thereby facilitating the work on adjusting the national guidelines in the Danish Neuro-Oncology Group.

Conclusion: The establishment of DNOR has optimized the quality in handling primary brain tumor patients in Denmark by reporting indicators and facilitating a better multidisciplinary collaboration at a national level. DNOR provides a valuable resource for research.

Keywords: brain neoplasms, brain cancer, glioma, clinical quality indicators

\section{Aim of database}

The Danish Neuro-Oncology Registry (DNOR) is a national clinical database collecting data on diagnostics and treatments in adult patients with primary brain tumors in Denmark. ${ }^{1}$ It was established with the purpose of supporting clinical development and research in this patient group.

The Danish Neuro-Oncology Group (DNOG) is developing and implementing national guidelines on treating adult brain tumor patients in Denmark. ${ }^{2}$ By the supply of data from DNOR, the discussions in DNOG are facilitated and performed on a more evidence-based background. A few key clinical quality indicators are selected in DNOR, giving each clinical department the opportunity to compare its own results to predefined standards and to reported national levels, and to follow-up on time trends of its own results. 


\section{Study population}

In Denmark (5.5 million inhabitants), approximately 1,550 patients are diagnosed with brain tumor each year and the incidence is increasing. Brain tumor diagnoses are classified by the International Classification of Diseases (ICD) codes and the Systematized Nomenclature of Medicine Morphology codes. ${ }^{3,4}$ The ICD-10 codes may be grouped into the following entities (Table 1): cerebral tumors, meningioma, sellae tumors, pineal tumors, neurinoma, and spinal tumors. Patients in each group are handled in different ways clinically, and accordingly, different data need to be registered. There is an ongoing work to include patients from all groups, but until now, the primary focus has been on glioma patients who make up the major part of adult brain tumor patients. These patients are identified by the M-codes given in the first row of Table 1. DNOR has included all patients diagnosed with glioma (excluding ependymoma) since January 1, 2009, which numbers approximately 400 patients each year.

\section{Main variables}

Data are registered in four different forms linked in a hierarchical data model (Figure 1). The forms including data on diagnostic and surgery are entered by the Department of Neurosurgery and the forms including data on chemotherapy and radiotherapy are entered by the Department of Oncology. The data are transferred to an analytical database which can describe the clinical course of the patients and administrative issues. Using the unique ten-digit code given to all Danish citizens, the analytical database is further linked to the Danish Civil Registration System ${ }^{5}$ to obtain residence and vital status.

Data contain information about symptoms, presurgical magnetic resonance imaging (MRI) characteristics, performance status, surgical procedures, residual tumor on postsurgical MRI, postsurgical complications, ICD-10 codes, Systematized Nomenclature of Medicine Morphology codes, radiotherapy, and chemotherapy.

Table 2 shows the indicators used in DNOR. There are two process and five results indicators describing survival, early postoperative MRI, surgical qualification, extent of surgical resection, postsurgical mortality, radiotherapy, and chemotherapy.

From 2009 to 2014, clinical data on 2,238 patients have been reported in DNOR, representing $92 \%$ of all cases identified in the central registries using the relevant diagnostic codes presented in the first row of Table 1 . In approximately $5 \%$ of the included patients, only oncological data were reported, while basic diagnostic and surgical data were missing. From 2015, the DNOR has been using algorithms from the standardized platform for the Danish Clinical
Table I List of relevant ICD-I 0 codes for DNOR and SNOMED $M$-codes, which defines the inclusion criteria for calculation of indicators in DNOR

\begin{tabular}{|c|c|c|}
\hline \multirow[t]{2}{*}{ Groups } & \multirow[t]{2}{*}{ ICD-I 0 codes } & \multirow{2}{*}{$\begin{array}{l}\text { SNOMED } \\
\text { M-codes }\end{array}$} \\
\hline & & \\
\hline \multirow[t]{14}{*}{ Cerebral tumors } & DD33.0-33.2 & M938I3, \\
\hline & DD33.7 & M93823, \\
\hline & DD33.9 & M9384I, \\
\hline & DD43.0-43.2 & M93853, \\
\hline & DD43.7+9 & M94003, \\
\hline & DC7I.0-7I.9 & M940I3, \\
\hline & $\mathrm{DC} 72.8$ & M94II3, \\
\hline & DC72.9 & M94213, \\
\hline & & M94243, \\
\hline & & M94253, \\
\hline & & M94403, \\
\hline & & M94423, \\
\hline & & M94503, \\
\hline & & M945I3 \\
\hline \multirow[t]{3}{*}{ Meningioma } & DD32.0-32.9 & \\
\hline & DD42.0-42.9 & \\
\hline & DC70.0-9 & \\
\hline \multirow[t]{6}{*}{ Sellae tumors } & DD35.2 & \\
\hline & DD35.3 & \\
\hline & DD44.3 & \\
\hline & DD44.4 & \\
\hline & DD75.I & \\
\hline & DD75.2 & \\
\hline \multirow[t]{3}{*}{ Pineal tumors } & DD35.4 & \\
\hline & DD44.5 & \\
\hline & DD75.3 & \\
\hline \multirow[t]{3}{*}{ Neurinoma } & DD33.3 & \\
\hline & DD43.3 & \\
\hline & DC72.2-72.5 & \\
\hline \multirow[t]{3}{*}{ Spinal tumors } & DD33.4 & \\
\hline & DD43.4 & \\
\hline & DC72.0-72.I & \\
\hline
\end{tabular}

Abbreviations: DNOR, Danish Neuro-Oncology Registry; ICD, International Classification of Diseases; M, morphology; SNOMED, Systematized Nomenclature of Medicine.

Cancer Registries, ${ }^{6}$ which will optimize the completeness of the identification of patients with brain tumors in DNOR.

\section{Follow-up}

Table 3 shows the results of clinical indicators from 2010 to 2014. There is a trend that postoperative MRI is performed in a higher proportion of patients (Indicator II) and another trend that a higher proportion of patients have no residual tumor after surgical resection of the primary tumor (Indicator IV). Further data are available in the annual reports from DNOR. ${ }^{7}$

\section{Examples of research}

DNOR provides an important source of clinical data for scientific investigations. The scientific utility demands 


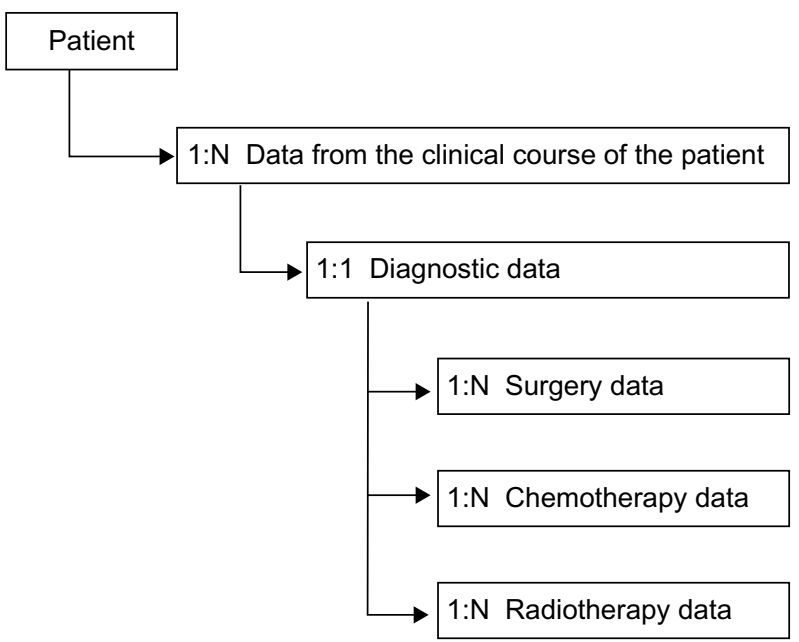

Figure I Data model of the Danish Neuro-Oncology Registry.

Table 2 Clinical quality indicators used in the Danish NeuroOncology Registry

\begin{tabular}{lll}
\hline Number & Descriptions & Standards \\
\hline Ia & $\begin{array}{l}\text { Proportion of patients who are alive I year } \\
\text { after surgery out of all patients in whom the }\end{array}$ & $\geq 50 \%$ \\
histological diagnosis is glioblastoma & \\
Ib $\quad \begin{array}{l}\text { Proportion of patients who are alive 2 years } \\
\text { after surgery out of all patients in whom the }\end{array}$ & $\geq 15 \%$ \\
histological diagnosis is glioblastoma & \\
II & Proportion of patients who have undergone \\
postoperative MRI no later than the & $\geq 90 \%$ \\
third day after primary surgery out of all & \\
patients who have undergone resection \\
and have contrast-enhancing tumor \\
(ie, suspected high-grade glioma) prior to \\
resection
\end{tabular}

Abbreviation: MRI, magnetic resonance imaging.

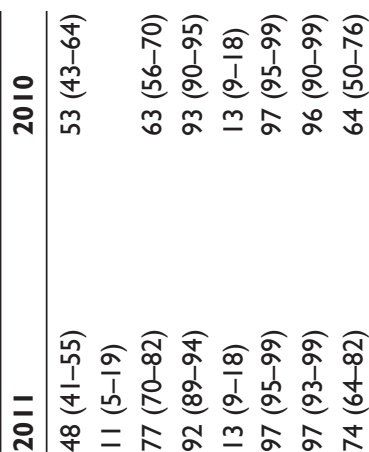

สิน

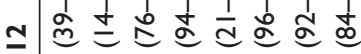
เั่

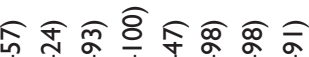

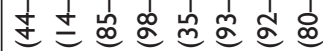
둔

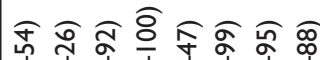

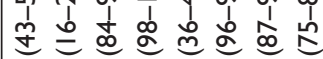
ㅎํ ๙

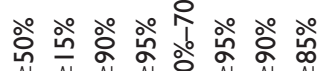
$\begin{array}{llllllll}n & N & N & 0 & N & N & N\end{array}$ 
completeness and validity of data. Hence, there is an ongoing research project with the purpose of evaluating the completeness of data as well as data validity. Furthermore, several epidemiological studies based on data from the initial 6 years from 2009 to 2014 are in progress. Generally, DNOR provides the opportunity for clinical research in glioma patients in a population-based setting. The possibility to link to other Danish national registries such as the Danish Civil Registration System, ${ }^{5}$ the Danish National Patient Registry, ${ }^{8}$ and the Danish National Pathology Registry ${ }^{9}$ further strengthens the research potential.

\section{Administrative issues and funding}

DNOR was established under the auspices of DNOG, which is the Danish Multidisciplinary Cancer Group on primary brain tumors in adult patients. DNOG members are appointed by the relevant member society under the Organization of Danish Medical Societies including neurosurgery, medical and radiation oncology, neurology, neuroradiology, pathology, and nuclear medicine. DNOR is financially supported by the Danish health care authorities through a national quality program organized in the Danish Clinical Registries. ${ }^{10}$ Also, there is technical support from the Registry Support Centre of Epidemiology and Biostatistics, South.

\section{Conclusion}

The establishment of DNOR has optimized the quality in handling primary brain tumor patients in Denmark by introducing clinical quality indicators and facilitating a better multidisciplinary collaboration at a national level. DNOR variables and indicators are selected by clinicians for the discussion of quality on a more reliable background on selected topics. This discussion takes place in DNOG with the possibility of simultaneous adjustment in national guidelines to optimize the implementation of procedures in clinical practice. Also, DNOR data are a useful research resource for the future.

\section{Acknowledgments}

This paper was funded by the Program for Clinical Research Infrastructure (PROCRIN) established by the Lundbeck Foundation and the Novo Nordisk Foundation and administered by the Danish Regions. The paper is written on behalf of the DNOR Steering Committee.

\section{Disclosure}

The author reports no conflicts of interest in this work.

\section{References}

1. DNOG.dk [homepage on the Internet]. The Danish Neuro-Oncology Registry. Available from: http://www.dnog.dk/database. Accessed November 19, 2015.

2. DNOG.dk [homepage on the Internet]. The Danish Neuro-Oncology Registry. Available from: http://www.dnog.dk/assets/files/ Retningslinier\%20PDF/DNOG-2014-Gliom-Retningslinje.pdf. Accessed November 19, 2015.

3. WHO.int [homepage on the Internet]. World Health Organization. Available from: http://www.who.int/classifications/icd/en/. Accessed November 19, 2015.

4. Patobank.dk [homepage on the Internet]. The Danish Pathology Register. Available from: http://www.patobank.dk/index.php?ID=18\&lang=da. Accessed November 19, 2015.

5. Pedersen CB. The Danish Civil Registration System. Scand J Public Health. 2011;39(7 Suppl):22-25.

6. RKKP.dk [homepage on the Internet]. The Danish Clinical Registries. Available from: http://www.rkkp.dk/drift-og-udvikling/den-nationalekliniske-kraftdatabase/. Accessed November 19, 2015.

7. DNOG.dk [homepage on the Internet]. The Danish Neuro-Oncology Registry. Available from: http://www.dnog.dk/database/aarsrapporter. Accessed November 19, 2015.

8. Lynge E, Sandegaard JL, Rebolj M. The Danish National Patient Register. Scand J Public Health. 2011;39(7 Suppl):30-33.

9. Bjerregaard B, Larsen OB. The Danish Pathology Register. Scand J Public Health. 2011;39(7 Suppl):72-74.

10. RKKP.dk [homepage on the Internet]. The Danish Clinical Registries. Available from: http://www.rkkp.dk/okonomi/. Accessed November 19, 2015.
Clinical Epidemiology

\section{Publish your work in this journal}

Clinical Epidemiology is an international, peer-reviewed, open access, online journal focusing on disease and drug epidemiology, identification of risk factors and screening procedures to develop optimal preventative initiatives and programs. Specific topics include: diagnosis, prognosis, treatment, screening, prevention, risk factor modification,

Submit your manuscript here: http://www.dovepress.com/clinical-epidemiology-journal

\section{Dovepress}

systematic reviews, risk \& safety of medical interventions, epidemiology \& biostatistical methods, and evaluation of guidelines, translational medicine, health policies \& economic evaluations. The manuscript management system is completely online and includes a very quick and fair peer-review system, which is all easy to use. 